\title{
Comunicação como poesia e humor: Mario Quintana
}

Adilson Citelli*

Graduado em Letras (1973), mestre em Literatura Brasileira (1982) e doutor em Literatura Brasileira (1990), todos pela Universidade de São Paulo. É professor titular do Departamento de Comunicações e Artes da ECA/USP e dos programas de graduação e pós-graduação, onde ministra cursos e orienta dissertações e teses nas áreas de Comunicação e Linguagem, com ênfase nas subáreas: Comunicacão/Educacão, Comunicação/Linguagem. É coeditor da revista Comunicação \& Educação**.

E-mail: citelli@uol.com.br

Não há comicidade fora daquilo que é propriamente humano. Uma paisagem poderá ser bela, graciosa, sublime, insignificante ou feia; nunca será risível. Rimos de um animal, mas por termos surpreendido nele uma atitude humana ou uma expressão humana. Rimos de um chapéu; mas então não estamos gracejando com o pedaço de feltro ou de palha, mas com a forma que os homens lhe deram, com o capricho humano que lhe serviu de molde. Como um fato tão importante, em sua simplicidade, não chamou mais a atenção dos filósofos? Vários definiram o homem como "um animal que sabe rir". Poderiam também tê-lo definido como um animal que faz rir, pois, se algum outro animal ou um objeto inanimado consegue fazer rir, é devido a uma semelhança com o homem, à marca que o homem lhe imprime ou ao uso que o homem lhe dál.

O riso é próprio do homem, conforme ensinado por Aristóteles na Poética. Essa afirmação é corroborada na vida de todos nós cada dia. Rimos de acontecimentos, de coisas, dos outros e de nós mesmos. Rimos para esquecer, para lembrar, para criticar ou simplesmente para se alegrar. Indiscutível é que o riso está tão amalgamado à sociedade e ao nosso ser que, conquanto o expressemos, pouco nos ocupamos em defini-lo. Tal assertiva não exclui o fato de uma série de pensadores terem-se dedicado ao assunto. De Platão a Kant, passando por George Bataille e chegando a Umberto Eco, várias são as manifestações acerca da presença do riso como indicador fundamental da vida humana².

Para produzir o riso, recorremos a jogos de palavras ou de ideias que desconstroem a realidade estabelecida - composta, também, de tabus, preconceitos e estereótipos -, formando, assim, uma nova ordem em que o inesperado e o inadequado são perfeitamente aceitáveis e verossímeis. Cria-se, a partir de então, o cômico, o jocoso, o humor, a ironia e a sátira que geram o riso.

Através da história das sociedades, o riso recebeu diversas interpretações e exerceu diferentes funções. Na Antiguidade, personificado pela comédia, era

\footnotetext{
* Com a colaboração de Cristine Vargas (revista Comunicação \& Educação - ECA/USP e FFLCH/ USP).

** É autor de inúmeros artigos e livros, dentre os quais se destacam: Linguagem e persuasão (Ática: 1994); Comunicação e educação: a linguagem em movimento (SENAC: 2000); Palavras, meios de comunicação e educação (Cortez: 2006).

1. BÉRGSON, Henri. O riso: ensaio sobre a significação da comicidade. São Paulo: Martins Fontes, 2001.

2. Ver: BÉRGSON, op. cit.; FREUD, Sigmund. Os chistes e sua relação com o inconsciente. Rio de Janeiro: Imago, 1999; ALBERTI, Verena. O riso e o risível na história do pensamento. Rio de Janeiro: Jorge Zahar, 1999.
} 
3. Ver: BAKHTIN, Mikhail. Cultura popular na Idade Média e no Renascimento. São Paulo: Hucitec, 2008

4. Cf. SALIBA, Elias Thomé. Raízes do riso: a representação humorística na história brasileira. $\mathrm{Da}$ Belle Époque aos primeiros tempos do rádio. São Paulo: Companhia das Letras, 2002. p. 19

5. Ibid., p. 29. instrumento de revelação dos vícios humanos, sendo, portanto, considerado inferior em contraposição à epopeia e à tragédia, gêneros tidos como superiores. Nesse sentido, a comédia mostrava como o homem não deveria ser, ou seja, modelo a não ser seguido.

Na Idade Média, o riso era tido por algo grotesco, que se opunha ao belo, ao sublime e à religiosidade, ficando à margem dos padrões ideológicos da época, conforme tematizado por Umberto Eco no romance $O$ nome da rosa. Contudo, mesmo naquela quadra histórica, o riso manifestava-se como forma de resistência popular ao poder, traduzindo-se nas festas populares, nas dinâmicas carnavalizadoras da cultura ${ }^{3}$.

A partir do século XVII, a cultura ocidental estabeleceu duas práticas do riso: o riso bom, positivo, expressão da alegria, e o mau riso, o negativo, que revela a depreciação. Limites e regras foram estabelecidos para as piadas e para as conversações espirituosas ${ }^{4}$. A despeito das barreiras construídas pela sociedade, o riso sobreviveu, criou raízes e dispõe, na sociedade contemporânea, de larga presença.

No Brasil, as marcas do riso, do cômico, da blague, estiveram sempre presentes como constituintes na formação da nacionalidade. Diante das conhecidas intercorrências que nos acompanharam desde o período colonial à construção do Estado moderno, o ser brasileiro vem recorrendo ao humor como forma de combate, de resistência ou mesmo de superação de certos imperativos dados pela realidade, em seu conjunto de patrimonialismo, desmando, autoritarismo, subsunção das camadas populares. Seguindo a perspectiva de Saliba ${ }^{5}$, analisar a representação humorística é explorar a linguagem e a construção de uma das narrativas da nacionalidade. Portanto, apreender o humor nos escritores é compreender também a nossa nação e o nosso contexto.

É com este argumento que apresentamos alguns poemas do gaúcho Mario Quintana, que deixou vasta obra publicada no Brasil e no exterior, compreendendo desde poesia, tradução, conto, crônica, jornalismo, até teatro. Durante anos, Mario Quintana manteve uma coluna, inicialmente na revista A província de São Pedro, e depois no Correio do Povo (entre 1953 e 1967), intitulada Do Caderno $\mathrm{H}$, material posteriormente reunido em livro. Como se poderá ler nos textos a seguir, o nosso autor fez do registro irônico, da paródia, da acentuada carga para o humor as marcas de um estilo que cruza ao mesmo tempo conteúdos críticos, tiradas de espírito, formulações curtas, trechos em formato haicai e uma aguda consciência da linguagem poética. Despido do sentimento de superioridade, Mario Quintana expressa o cotidiano rompendo com motivos literários consagrados, desvelando máscaras sociais, denunciando a hipocrisia que circunda determinadas relações sociais, e no interior das quais também se vê envolvido. O leitor se reconhece nos seus textos e encontra no humor do poeta um espaço para a superação de certos limites impostos pela realidade. Dele se pode dizer, enfim, que ri do mundo, dos outros e de si mesmo. Talvez se registre neste movimento a sua grande peculiaridade. 


\section{ELEMENTOS BIOGRÁFICOS}

Mario Quintana nasceu em Alegrete, no dia 30 de julho de 1906, iniciando os estudos em 1914, na Escola Elementar Mista de Dona Mimi Coutinho. No ano de 1919, matriculou-se no Colégio Militar de Porto Alegre, em regime de internato, local onde produziu os seus primeiros trabalhos.

Em 1924, deixou o Colégio por motivos de saúde e empregou-se na Livraria do Globo. Em 1926, venceu o concurso promovido pelo jornal Diário de Notícias, de Porto Alegre, com o conto A sétima personagem. Em 1929, passou a integrar a redação do diário O Estado do Rio Grande.

No ano de 1934, foi publicada Palauras e sangue, tradução de uma obra de Giovanni Papini. A partir de então, o autor passou a traduzir para a Editora Globo obras de importantes escritores estrangeiros, tais como Proust, Voltaire, Virginia Woolf, Maupassant etc.

Em comemoração aos 60 anos do poeta, em 1966, foi publicada sua $A n$ tologia poética, organizada por Rubem Braga e Paulo Mendes Campos. Nessa ocasião, Mario Quintana foi saudado na Academia Brasileira de Letras por Augusto Meyer e Manuel Bandeira.

Quintana concorreu por três vezes a uma vaga na Academia Brasileira de Letras, mas não foi eleito. Perdida a terceira indicação, compôs o célebre Poeminha do contra:

Todos esses que aí estão

Atravancando meu caminho,

Eles passarão...

Eu passarinho!

Ao ser convidado a candidatar-se pela quarta vez, recusou-se, mesmo sob a promessa da unanimidade em torno de seu nome.

No dia 17 de julho de 1980, recebeu o Prêmio Machado de Assis conferido pela Academia Brasileira de Letras pelo conjunto de sua obra.

Em 1982, a Assembleia Legislativa do Rio Grande do Sul tombou o antigo prédio do Hotel Majestic, onde o autor viveu durante anos, como patrimônio histórico do Estado, passando a denominar-se Casa de Cultura Mario Quintana.

Aos 80 anos, em 1986, publicou a coletânea 80 anos de poesia e lançou Baú de espantos, uma reunião de 99 poemas inéditos.

No dia 5 de maio de 1994, em Porto Alegre, aos 86 anos, faleceu o poeta e escritor Mario Quintana.

\section{POESIAS}

\section{Libertação}

A morte é a libertação total:

a morte é quando a gente pode, afinal, estar deitado de sapatos...

(A vaca e o hipogrifo) 
comunicação \& educação • Ano XIV • Número 2 - maio/ago 2009

\section{O pior}

O pior dos problemas da gente

é que ninguém tem nada com isso.

(Caderno H)

\section{Leituras}

Não, não te recomendo a leitura de Joaquim Manuel de Macedo ou de José de Alencar. Que ideia foi essa do teu professor?

Para que havias tu de os ler, se tua avozinha já os leu?

E todas as lágrimas que ela chorou,

quando era moça como tu,

pelos amores de Ceci e da Moreninha,

ficaram fazendo parte do teu ser,

para sempre.

Como vês, minha filha,

a hereditariedade nos poupa

muito trabalho.

(Caderno H)

\section{A carta}

Quando completei quinze anos,

meu compenetrado padrinho

me escreveu uma carta muito,

muito séria: tinha até ponto e vírgula!

Nunca fiquei tão impressionado na minha vida.

(Caderno H)

\section{Ars longa}

Um poema só termina por acidente de publicação

ou de morte do autor.

(Caderno H)

\section{Biografia}

Era um grande nome - ora que dúvida!

Uma verdadeira glória. Um dia adoeceu, morreu, virou rua...

E continuaram a pisar em cima dele.

(Caderno H)

\section{Feira de livro}

O que os poetas escrevem agrada ao espírito, embeleza a cútis e prolonga a existência.

(Caderno H) 


\section{Gestos}

A mão que parte o pão

a mão que semeia

a mão que o recebe

- como seria belo tudo isso se não fossem

os intermediários!

(A vaca e o hipogrifo)

\section{O trágico dilema}

Quando alguém pergunta a um autor

o que este quis dizer,

é porque um dos dois é burro.

(Caderno H)

\section{Refinamentos}

Escrever o palavrão pelo palavrão

é a modalidade atual

da antiga arte pela arte.

(Caderno H)

\section{A Esfinge}

$\mathrm{Na}$ volta da esquina encontrei a Esfinge.

Petrifiquei-me.

Ela me disse então,

olhando-me nos olhos:

- Devora-me ou decifro-te!

(Caderno H)

\section{Camuflagem}

A esperança é um urubu pintado de verde.

(Caderno H)

\section{Ópera}

"Diz isso cantando!"

Lembram-se desse ditado?

A Ópera levou esse ditado a sério.

(Caderno H) 
comunicação \& educação • Ano XIV • Número 2 - maio/ago 2009

\section{Dos livros}

Há duas espécies de livros:

uns que os leitores esgotam,

outros que esgotam os leitores.

(Caderno H)

\section{Compensações}

Já repararam?

A má reputação

sempre faz parte da fama...

(Caderno H)

\section{A grande surpresa}

Mas que susto não irão levar

essas velhas carolas

se Deus existe mesmo...

(Caderno H)

\section{Evolução}

O que me impressiona, à vista de um macaco, não é que ele tenha sido nosso passado:

é este pressentimento de que ele venha a ser nosso futuro.

(Caderno H)

\section{O homem que não suportava cerimoniais}

- De repente, ele não pôde mais e rebentou de riso em plena missa de corpo presente.

- Ele quem?

- Ora, o defunto...

(Caderno H)

\section{A imagem e os espelhos}

Jamais deves buscar a coisa em si,

a qual depende tão somente dos espelhos.

A coisa em si, nunca: a coisa em ti.

Um pintor, por exemplo, não pinta uma árvore:

ele pinta-se uma árvore.

E um grande poeta - espécie de Rei Midas à sua maneira -

um grande poeta, bem que ele poderia dizer:

- Tudo o que eu toco se transforma em mim.

(Caderno H) 


\section{Contrição}

Bem que eu desejaria entender tanto de poesia como certos críticos, mas aí, então, não conseguiria fazer um único verso...

(Caderno H)

\section{Dolorosa interrogação}

Por que será que a gente vive chorando os amigos e não aguenta os que continuam vivos?

(Caderno H)

\section{Lavoisier}

Nada se perde, tudo muda de dono.

(Caderno H)

\section{REFERÊNCIAS BIBLIOGRÁFICAS}

FERNANDES, Mônica Luiza Socio. Ecos clássicos na moderna poesia de Quintana. 2001. Dissertação (Mestrado em Letras, Estudos Literários) - Programa de PósGraduação, Universidade Estadual Paulista Júlio de Mesquita Filho - Unesp, Araraquara, 2001.

QUINTANA, Mario. A vaca e o hipogrifo. 4. ed. Porto Alegre: L\&PM, 1983.

Caderno H. 2. ed. São Paulo: Globo, 2006.

SALIBA, Elias Thomé. Raízes do riso: a representação humorística na história brasileira. Da Belle Époque aos primeiros tempos do rádio. São Paulo: Companhia das Letras, 2002.

\section{Endereços eletrônicos}

Mario Quintana. Disponível: em <http://www.releituras.com/mquintana_bio. asp>. Acesso em: 14 abr. 2009.

Site comemorativo do centenário de Mario Quintana. Disponível em: <http:// www.estado.rs.gov.br/marioquintana/>. Acesso em: 14 abr. 2009. 


\section{Assine a revista Comunicação \& Educação}

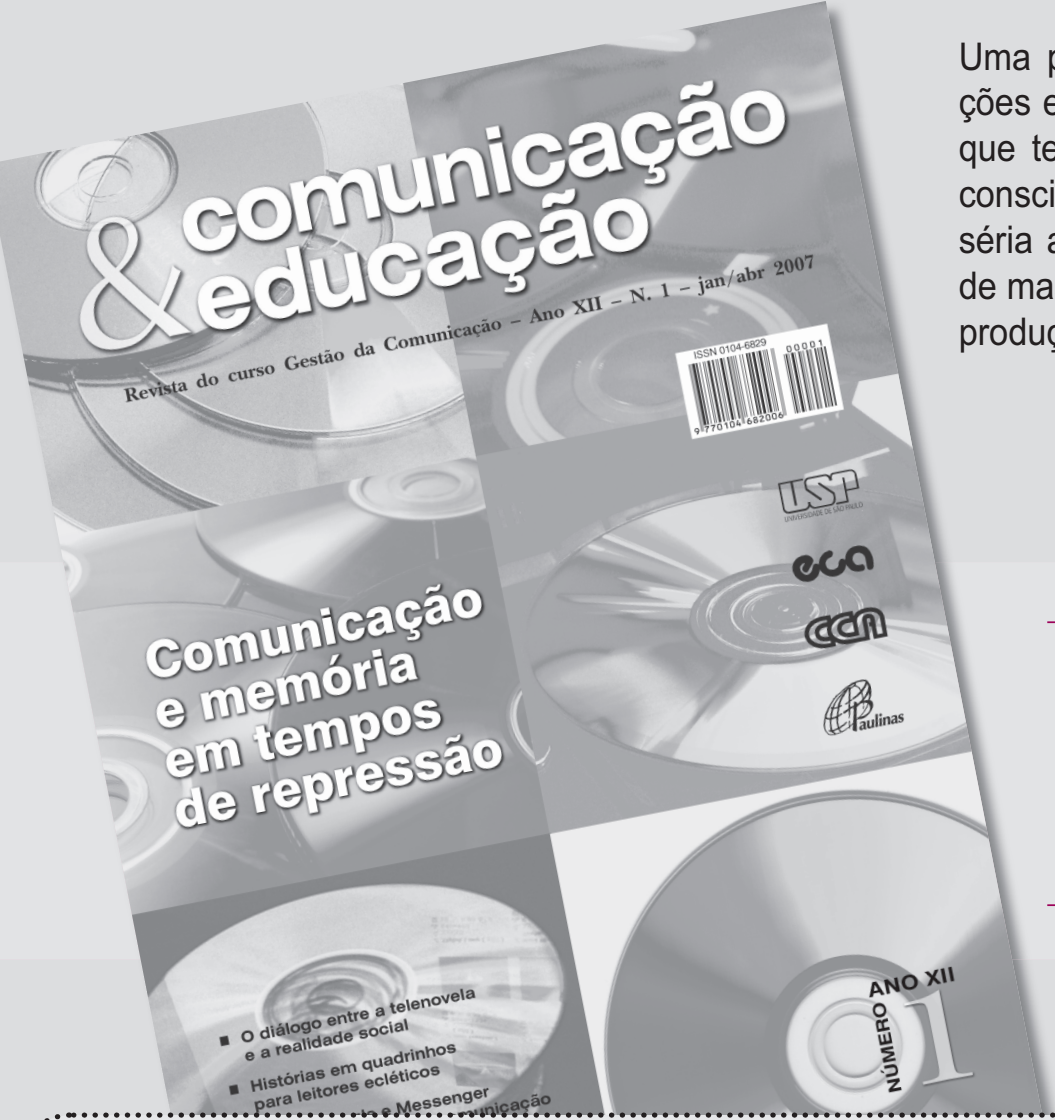
Ensaios, entrevistas e debates com os maiores especialistas da área auxiliam educadores a incluir em suas práticas novas linguagens e novos recursos pedagógicos.

\section{ADQUIRA TAMBÉM OS EXEMPLARES AVULSOS!}
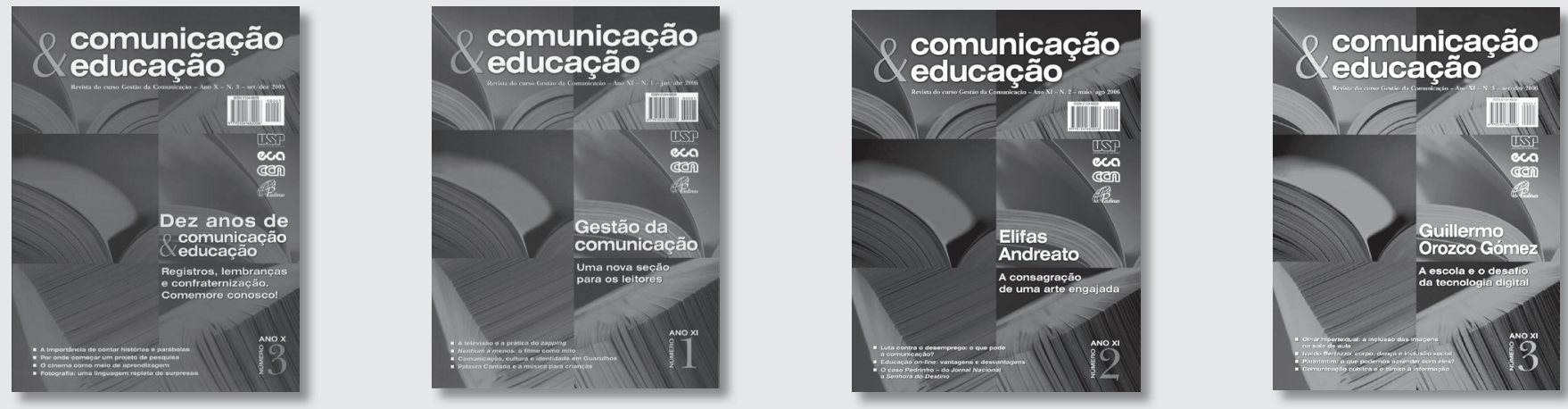

\section{VOCÊ ESCOLHE COMO QUER PAGAR!}

- Cartão de crédito - Visa, Mastercard ou Diners • Boleto bancário

- Depósito bancário identificado • DOC ou transferência bancária

\section{Ligue 0800-7010081 ramal 9448 ou assine}

pela livraria virtual Paulinas, acessando www.paulinas.org.br Informações: livirtual@paulinas.com.br 